\title{
Students-as-insurers: rethinking 'risk' for disadvantaged young people considering higher education in England
}

\author{
Neil Harrison
}

Department of Education and Childhood, University of the West of England, Coldharbour Lane, Frenchay, Bristol, BS16 1QY. E-mail: neil.harrison@uwe.ac.uk.Telephone: 01173284190.

\begin{abstract}
The conventional view since the early 2000s has been that participation in higher education (HE) is a risky pathway for disadvantaged young people in England; the social risk of entering an alien environment combines with the financial risk of rising costs and questionable long-term returns. This riskiness has been constructed as a major barrier to participation.
\end{abstract}

However, national administrative data cast doubt on whether this analysis still holds true. Despite significant rises in tuition fees, the proportion of disadvantaged young people entering HE has continued to rise, with advantaged groups seemingly being more price-sensitive. Data from recent qualitative studies has also suggested that young people are now less attuned to risks.

This paper considers whether circumstances in wider society have shifted perceptions of risk. The volatility resulting from the global financial crisis appears to have repositioned HE as a less risky option than early entry to the labour market, especially with more jobs becoming 'graduate', while the social risk has declined as HE has diversified. The paper draws on theoretical perspectives from Beck, Boudon, Simon and Kahneman to argue that many disadvantaged young people now view HE as a form of 'insurance' against an uncertain future.

Keywords: higher education, risk, investment, insurance, labour market 


\section{Introduction}

In England ${ }^{1}$, there has been a policy interest in increasing the participation in higher education (HE) for over fifty years, effectively starting with the publication of the Robbins Report (1963), which established a meritocratic principle that places should be available for all those qualified to benefit from one, regardless of means. The Dearing Review (National Committee of Inquiry into Higher Education [NCIHE], 1997) examined progress against this goal from a statistical perspective and demonstrated that strong differences in participation rates persisted by social class, ethnicity and gender. The last twenty years have seen an enduring policy aim by successive governments to close these gaps. For example, the latest White Paper sets an objective

to double the proportion of people from disadvantaged backgrounds entering university in 2020 compared to 2009 , and to increase the number of black and minority ethnic (BME) students going to university by $20 \%$ by 2020 (Department for Education [DfE], 2016, 14).

Despite this overarching policy aim, the period has also seen a rapid increase in the cost of HE, with tuition fees introduced in 1999 and rising to up to $£ 9,000$ a year from 2012; students now bear the full cost of their education on most courses.

The latest official figures (DfE, 2017) demonstrate that the gap in participation rates identified by Dearing (NCIHE, 1997) persists, albeit that there has been sustained, if modest, progress in the intervening period. This has been stronger among minority ethnic communities, where participation rates are now generally commensurate with, or higher than, the white majority group (Universities and Colleges Admissions Service [UCAS], 2016). Women now have a higher propensity than men to enter HE, although concerns remain about their participation in certain subject areas (e.g. engineering).

Concepts of 'disadvantage' are therefore somewhat fluid within the field, with different agencies in the HE sector using conflicting criteria and measures to classify young people. For example, the DfE use previous eligibility for free school meals (a means-tested provision and so a marker for the lowest income families), while UCAS prefer to identify young people living in areas with low historic participation in HE (Harrison and McCaig, 2015). Fortunately, these measures, which are broadly

\footnotetext{
${ }^{1}$ Because of the devolved nature of the United Kingdom, the education systems across the four constituent nations is markedly different. This paper will focus primarily on England, which comprises around $85 \%$ of the HE sector in the $\mathrm{UK}$, although some of the statistics used relate to the UK as a whole.
} 
cognate with the older focus on occupational status, tell similar stories despite their different foundations. Therefore, the broad sweep argument in this paper will employ an indicative socioeconomic binary (advantaged/disadvantaged) within this tradition; it is fully appreciated that this hides intersectional complexities with gender, ethnicity and disability.

The paper begins by examining the academic discourse from the early 2000s concerning the barriers preventing disadvantaged young people from participating in HE. This suggested that, inter alia, financial concerns and concerns about social alienation were major determinants in whether young people sought access to HE, specifically framing whether or not it was viewed as a 'risky' option.

It then moves on to explore concepts of 'risk' through a series of theoretical lenses from sociology and psychology to argue that societal changes in late modernity have shifted the nature of decisionmaking for young people and, specifically, they are more likely to seek dependable options over those with higher levels of risk; there is some empirical evidence that this is particularly true for disadvantaged young people. This is particularly the case with respect to avoiding downward social mobility during a period of economic recession.

The paper then develops this argument by examining recent trends in HE participation and youth unemployment as a springboard to critique the earlier literature, arguing that it has been overtaken by two key events which have repositioned HE vis-à-vis the options available to young people and perceptions of their relative 'riskiness'. Firstly, the 2008 global financial crisis has radically altered the nature of the youth labour market, with high unemployment through the early 2010s and continuing trends of low-wage and insecure work. Secondly, the early 2010s saw HE become a nearmajority pursuit for young people, altering perceptions about social risks, as well as resulting in a downward creep in what are considered to be 'graduate' jobs and reducing the availability of highquality work for school-leavers.

It is argued that, during a period of societal turbulence, young people increasingly view HE as a form of insurance to guarantee an acceptable standard of living, rather than as an investment to maximise their lifetime income. This is particularly true for disadvantaged young people whose demand remains buoyant despite rising costs and labour market congestion. This argument is necessarily somewhat speculative in nature, but it provides a lens on young people's decision-making that is consistent with the national data presented and forms a meaningful framework for future empirical work. 


\section{Risk and disadvantaged students}

Risk is something of a slippery concept. In everyday speech, risk is often constructed as negative, but it is really an unavoidable feature of human existence. Some pleasurable experiences can only be enjoyed by accepting some possibility of a negative outcome (e.g. scuba diving), while some individuals find risk itself to be a pleasurable experience. The amount of risk to which a young person is exposed generally rises towards adulthood (France, 2000), when increasingly frequent decisions are required that will exert a significant influence on their future life chances.

Mainly dating to the early 2000s, there is an extensive literature exploring the views of disadvantaged young people, from the perspectives of those already in HE, those of an age to be considering it and those who had chosen to be outside of it. A key feature of this literature, which is too large to review in detail here, is a discourse around the riskiness of HE.

For example, Archer and Hutchings $(2000,569)$ reported on focus groups of non-participants aged 16 to 30 who saw HE as 'inherently risky, demanding great investment and costs, and yielding uncertain returns'. The risks included the possibility of academic failure, the inability to cover costs and a sense of identity loss, while there were fears about whether there would be any return on the investment. Ball et al. $(2002,69)$ found that disadvantaged young people in schools and further education colleges feared social isolation due to the classed structures and norms of HE: 'The risks and reflexivity $[\ldots]$ of the working classes are about being different people in different places, about who they might become and what they must give up'. Archer, Pratt and Phillips $(2001,444)$ researched young men in London all of whom 'shared a disadvantaged position in relation to potential higher education participation; whereby participation constituted an economically, socially and culturally more difficult and riskier option'. Clayton, Crozier and Reay $(2009,170)$ highlight 'the risks and insecurities disproportionately encountered by working-class students', while Patiniotis and Holdsworth $(2005,92)$ conclude that 'government rhetoric couches HE in terms of opportunity - but for working-class students, the opportunity of HE brings attendant risk'.

In particular, mounting HE costs were juxtaposed with uncertain graduate job prospects. Callender and Jackson $(2005,534)$ argue that 'with rising student debt, entering HE is an increasingly risky investment decision for low-income students', arguing that as they take on more student loans the less they stand to gain: 'the greater the risks and the higher the debt, the lower the rates of return on HE'. Archer and Hutchings $(2000,568)$ assert that 'the new system of loans may indeed deter both 
those who are interested in going to university and those who are not so keen', while Leathwood and O'Connell $(2001,613)$ conclude that 'it seems highly likely, therefore, that poorer students will either be put off completely, or will choose their course and university according to what they can (or cannot) afford.'

This brief flavouring of a rich literature is intended to illustrate the unanimity of this historical discourse of riskiness: (a) a social risk about entering an institution traditionally associated with hegemonic power; and (b) a financial risk of forgone earnings, accumulating debt and uncertain returns. There are also two relational dimensions - that advantaged young people are generally exposed to lower risks and that entry to the labour market is less risky than continued education. This paper examines and theorises how social changes in the intervening period may have impacted on perceptions of social and financial risks, and what this has meant for behaviours with respect to HE entry.

\section{Risk, decision-making and uncertainty}

Ulrich Beck's (1992) conceptualisation of the 'risk society' has had a far-reaching impact on social science. In summary, his main argument is that late modernity has seen a breaking down of established structures and social relations, largely as the result of increased technological advancement and globalisation. For Beck, the traditional pathways into and through the labour market have diminished and replaced by a diversified life course. This individualisation requires greater reflexivity across a greater number of decisions, compared to early modernity's relative simplicity and predictability, where transitions were strongly marked by the structures of gender and class:

'The proportion of life opportunities which are fundamentally closed to decision-making is decreasing and the proportion of the biography which is open and must be constructed personally is increasing' (Beck, 1992, 135).

Beck argues that while this has opened up new options (including those that can enable upward social mobility), the associated anxiety of ambiguity and the loss of social bedrock institutions has limited individuals' ability to take advantage of these options. Furthermore, the 'loss of traditional security' (Beck, 1992, 128) has seen individuals more likely to be held to account (e.g. through unemployment) for their personal decisions and 'failures'. 
Bourdieusian writers such as Atkinson (2007), Roberts (2012) and Burke (2017) argue that Beck's vision of the risk society is limited in its explanatory power as it overstates the collapse of social structures and overemphasises the ability of the individual to exercise agency. Woodman (2009) contends that this is a misreading and that Beck's case is that traditional structural factors have declined in value as analytical categories, but that their role in shaping inequalities and social reproduction persists, but in altered forms. Indeed, a number of theories have been proposed to resolve this tension, including 'bounded agency' (Evans, 2007) and 'horizons for action' (Hodkinson and Sparkes, 1997) which stress the structural constraints on the choices available to young people derived from sites of inequality, while accepting that there are individualised decisions required in navigating the new options and pathways that have opened up.

This debate is relevant to the argument I am seeking to develop and I will return to it later, although without resolution. However, my main focus is a contention, based on Beck, that late modernity has seen an increase in (a) the number of decisions required of young people, (b) the number of options within these decisions, and (c) the unpredictability of the outcomes of these options. I will use 'decisions' to mean branching points in a young person's life where an action of pursuing one of multiple options (possible courses of action) is required, while 'choices' are the collective set of options which appear available and valid to the individual, influenced by social structures, personal circumstances and other factors (e.g. luck).

One subset of decisions facing young people is that relating to entry into the labour market and the amount of education they decide to accumulate prior to doing so; although this trade-off has become less clear-cut with the increasing diversity of mixed options available (e.g. through various blends of work and study). In his specification of 'human capital theory', Becker (1993) predicts that an extended education will lead to increased lifetime income, especially within knowledge-based economies where educational credentials are valorised as a means of predicting workers' productivity. Under this model, post-compulsory education becomes a form of investment about which individuals can make rational decisions. The outlay can be directly (e.g. tuition fees and living costs) or indirectly (through forgone wages while studying) financial, with an expectation of a returnon-investment; with respect to HE, this is often known as the 'graduate premium'. While human capital theory has enjoyed prominence, it has also come under critique from post-materialist perspectives that argue that educational and career decisions are increasingly driven by concerns beyond the financial, including flexibility, self-expression or social activism. This was seen clearly in Atfield and Purcell's (2010) analysis, where students (and particularly women) rated work-life 
balance, job security and opportunities for training/promotion as more important than salary, with socially-useful work close behind. In other words, while a form of investment undoubtedly exists, the individual may not seek to maximise the long-term financial utility in the ways predicted by Becker. Furthermore, there may also be consumptive elements of the HE experience that are valued outside of their role in providing access to careers; I will return to this later.

It has long been understood that disadvantaged young people tend to leave education earlier than their advantaged peers. Boudon's (1974) major contribution to the sociology of educational decisionmaking has been the hypothesis that the lower overall take-up of educational opportunity by disadvantaged groups is comprised of two separate effects: (a) lower qualifications allowing progression (which he called the 'primary effect'), and (b) a lower propensity to demand education even accounting for qualification differentials (the 'secondary effect'). Subsequent work by researchers in this 'rational action' tradition (see Thompson, 2017 for an overview) have theorised and empirically explored the nature of Boudon's secondary effects, focusing on various elements including the perceived likelihood of academic success, a willingness to invest and the prevailing costs of education. In addition, consistent with the literature reviewed earlier, the secondary effect is likely to include the extent to which disadvantaged groups expect to feel socially comfortable in the next stage of education - whether it includes 'people like me'.

Perhaps most importantly, Boudon asserts that there is a universal desire to avoid downward social mobility - i.e. for young people to attain at least the social standing (and standard of living) of their parents. This is something of a reversal of traditional human capital theory, which views education as a positive long-term investment rather than as a means of mitigating a risk. Following Boudon's work, Breen and Goldthorpe (1997) argued that this presupposes a higher average propensity to demand education among advantaged young people as the maintenance of their status requires a higher level of educational attainment than for their disadvantaged peers - a higher 'relative risk aversion' (Thompson, 2017) to downward social mobility. However, Stocké (2007) and Obermeier and Schneider (2015) present empirical evidence that suggest this desire to maintain social status is actually somewhat stronger among disadvantaged young people. I shall return to these ideas later.

Finally, I turn to the linked contributions of Herbert Simon and Daniel Kahneman. While Boudon, Goldthorpe and Breen were writing as sociologists and were concerned primarily with average effects across social groups, my argument now shifts to the discipline of psychology and its focus on the individual. Simon's (1955) foundational fieldwork was undertaken on decision-making in organisational settings, but he rapidly expanded it out to encompass any situation where there are 
competing options with probabilistic outcomes under the guise of 'bounded rationality' $(1979,1997)$. Simon argued that while humans may aspire to taking rational decisions in terms of maximising the outcomes, this becomes impossible if the complexity of the decision becomes too great, for example, through too many options, conflicting ideas of value, unknown outcomes and unknown probabilities of those outcomes:

'Rationality is bounded when it falls short of omniscience. And the failures of omniscience are largely failures of knowing all the alternatives, uncertainty about relevant exogenous events, and inability to calculate consequences' (Simon, 1979, 502).

I argue that bounded rationality is a useful lens for understanding the nature of the decisions facing young people for whom $\mathrm{HE}$ is a possible option by dint of their qualifications. For the sake of developing the argument, let us assume that the principal choice is dichotomous between entering HE and entering the labour market through a good job or apprenticeship - two broadly positive options, but the latter offering a more immediate, and therefore more predictable, outcome. There is also a wider set of secondary choices derived from the stratified and marketised nature of HE - what type of university, what subject area, whether to move away to study, whether to attend the same university as friends for social comfort and so on.

There is a growing body of analysis around the outcomes from degrees. The three most important determinants of graduate salary appear to be status of university, discipline of degree and degree classification achieved (Walker and Zhu, 2011; Naylor, Smith and Telhaj, 2016). Disadvantaged young people may not decide to maximise the status of the university they attend due to family commitments or fears about social fit (Whitty, Heyton and Tang, 2015), while the discipline of degree has to be traded off against a consumptive element of HE - i.e. the need to enjoy the subject, at least to an acceptable level the spend three years on it. Degree classification is a function, inter alia, of effort which is partly within the control of the young person, but mediated through their personal circumstances and their enjoyment of the discipline and feelings of being part of a supportive community (Thomas, 2012). Final salary is then also influenced by the ability to be geographically mobile, competence and effort in job searching, social capital and a myriad of other factors, including simple luck.

The previous paragraph illustrates the sheer complexity of the seemingly simple decision on whether or not to enter HE, which is then overlaid with the choice between around 150 universities and tens of thousands of individual programmes (see Harrison, 2017a for a more detailed treatment). Put 
another way, if we are expecting young people to rationally decide on entering HE, we are asking them to estimate what their abilities and effort levels might be in three years' time across a range of possible subjects or universities: 'Having witnessed the struggles of econometricians to learn the returns to schooling, I find it difficult to accept the proposition that adolescents are endowed with this knowledge' (Manski, 1993: 49, cited in Brynin, 2017). Indeed, Green and Zhu (2010) chart the wide variance in graduate salaries, while Jerrim (2011) finds that graduates tend to significantly overestimate their starting salary, especially in the early stages of their studies (i.e. soon after the decision to enter).

Using Simon's lens, HE decisions transcend ideas of risk, where the individual is able to weigh potential outcomes and their estimable likelihoods before arriving at a decision. We have seen the challenges of estimating the return-on-investment from HE, but the same applies to early entry to the labour market; I shall shortly argue that this is particularly true in periods of economic instability. Instead, these decisions enter the realm of uncertainty, where the outcomes of the options are probabilistic and, where there is insufficient knowledge to form useful a priori estimates of either the value of the possible outcomes (in the broadest sense) or their likelihood of coming to pass. This is consistent with Beck's idea of the 'risk society' where the predictability of pathways into the labour market has fallen due to shifts in social structures and people's perceptions of them, with young people being particularly susceptible (Furlong and Cartmel, 2006).

Simon $(1979,1997)$ argues that in these situations, humans will tend to use an intuitive form of decision-making which he called 'satisficing'; meeting minimal criteria for success without seeking to maximise the outcome. This intuitive and emotional element to decision-making under uncertainty is supported by experimental studies by Daniel Kahneman (Kahneman and Tversky, 1997; Kahneman, 2003). The problem with intuitive decision-making is that it is difficult to model and use as the basis for action in policy or practice. Nevertheless, Kahneman has built on Simon's work to develop his 'prospect theory' to enable predictions about behaviour to be constructed and a number of elements are relevant here. Firstly, people tend to be loss-averse rather than uniformly risk-averse - i.e. the prospect of a loss weighs more than the chance of a gain. Secondly, their loss-aversion grows with uncertainty; the danger of an unknown loss is a powerful disincentive. Thirdly, lossaversion is related to economic resources, such that people with less to lose tend to be more lossaverse. In addition, Kahneman (2003) has demonstrated that, under uncertainty, people will tend to intuitively rely on information that is readily brought to mind, either through personal familiarity or prevailing stereotypes. 
My argument to date is that, following Beck, late modernity represents a period where (some) old certainties have broken down and where young people are being required to take more decisions, with more options (although not necessarily greater choice), where the outcomes of each option are probabilistic and hard to estimate. Under such uncertainty, I have argued that Simon's lens of bounded rationality and Kahneman's prospect theory apply, with young people likely to be intuitive, loss-averse and reliant on readily-available information to frame a satisficed decision that meets a minimal level of acceptability and certainty without necessarily being optimal. While this is a challenge to the assumption of rational action underpinning Boudon's approach, the loss-aversion identified by Kahneman is wholly congruent with Boudon's focus on avoiding downward mobility; Kahneman's work would further predict that this would be strongest among disadvantaged young people, which is consistent with the findings of Stocké (2007) and Obermeier and Schneider (2015). I will now turn to examine national administrative data to contextualise my argument further.

\section{Recent trends: HE participation}

The last two decades have seen a wealth of published data on HE participation. Analysis is somewhat hampered by shifting definitions and alternative datasets, but one clear trend has been the increasing proportion of young people participating in HE. At the time of the Robbins Report (1963), around five percent participated, rising to 32 percent by the time of the Dearing Review (NCIHE, 1997). It has continued to rise and the latest official figures reveal that 43 percent of young people in England entered HE in 2016 at either 18 or 19 (UCAS, 2016). HE has ceased to be an elite pursuit and it is fast approaching the point where the majority of young people will participate - this tipping point has already been reached once a slightly wider age range is considered. The rates are higher still among young women (47 percent, compared to 36 percent of young men), while advantaged young people continue to be significantly more likely to enter HE, albeit that the gap has closed slightly in recent years (DfE, 2017, UCAS, 2016). There has been a sustained growth in the numbers of students from minority ethnic communities participating such that they now comprise around 20 percent of the total (Higher Education Statistics Agency, 2018), with participation rates for most groups exceeding those of the white majority group.

However, the highly stratified nature of the HE sector means that participation is not evenly distributed. Advantaged young people are significantly more likely to be found in higher-status universities whose demographic composition has barely changed in twenty years (Croxford and Raffe, 2015; Raffe and Croxford, 2015; Harrison, 2017b). In part this is due to difference in school 
qualification levels, but there is also likely to be an element of preference for local and more sociallycomfortable options (Whitty, Hayton and Tang, 2015). As a result, most of the growth in disadvantaged student numbers has been focused in lower-status universities. In particular, students from minority ethnic communities are considerably less likely to enter higher-status universities, which Boliver (2016) has demonstrated is not solely a matter of qualification or preference.

While expanding and, to some extent, diversifying, HE has also become markedly more expensive. In 1997, most students were able to access a mixture of means-tested grants and loans for maintenance and there were no tuition fees. Maintenance support has since switched to all loans (2001), a mix of grants and loans (2004) and then back to larger loans (2016), plus university-based bursaries from 2006. Tuition fees of $£ 1,000$ were levied in 1998, raised to a maximum of $£ 3,000$ in 2006 and $£ 9,000$ in 2012. It was widely argued that these rising costs in the form of accumulated debt would deter students - and disproportionately those from disadvantaged backgrounds (Archer and Hutchings, 2000; Callender and Jackson, 2005; Jones and Thomas, 2005; Leathwood and O'Connell 2001).

Figure 1: HE participation rates for 18-year-olds by POLAR quintile from 2004 to 2014 (Source: UCAS, 2006)

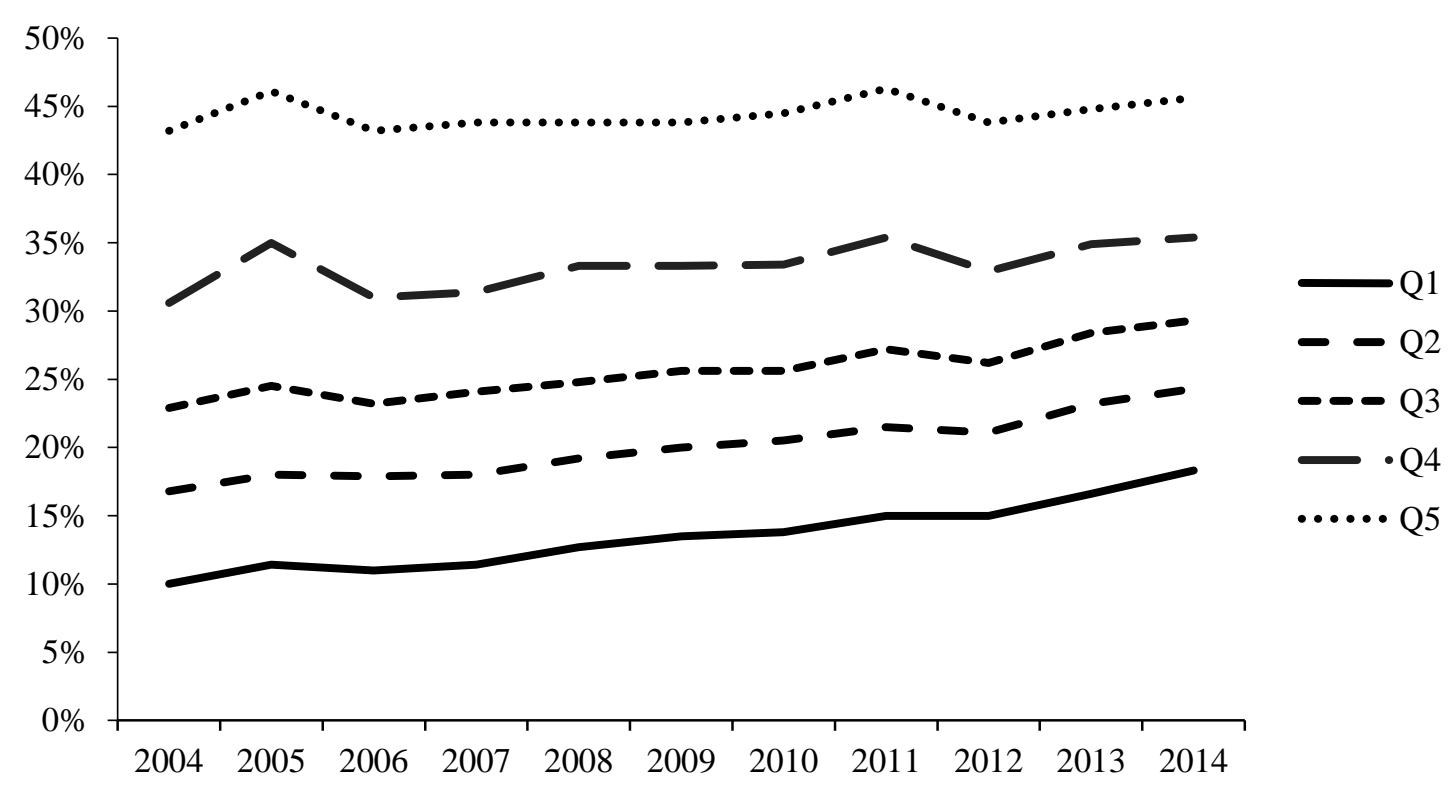

However, the data do not bear this out (see Harrison, 2017b for a more detailed analysis). Figure 1 uses the POLAR statistic, which divides local government wards into five quintiles on the basis of historical HE participation rates and then allocates young people to the quintile based on their pre- 
HE residence (see Higher Education Funding Council for England, 2005, 2010 for a full explanation) - Quintile 1 represents areas with the lowest historic participation rates, with Quintile 5 representing the highest; POLAR therefore acts as an area-based proxy for disadvantage. As can be seen, there has been an overall increase in participation over time across all the quintiles, with some narrowing of the gaps between them.

Importantly for my argument, while there is a clear impact of the increases in tuition fees in 2006 and 2012, this does not take the form predicted by earlier literature. Rather than impacting by suppressing demand from Quintile 1, which was the group felt to be most likely to be affected by the changes, the impacts are mainly seen in Quintiles 4 and 5 where there is brief increase in participation before the increases are implemented (most likely representing forgone 'gap years' - Harrison, 2017b), followed by a fall in demand at the point of implementation.

Additional data presented in UCAS (2016) shows that this impact was particularly strongly felt in lower-status universities, while demand from disadvantaged groups (i.e. Quintiles 1 and 2) retained its upward trend in spite of the tuition fee increases. In other words, the group seemingly most influenced by the changes were actually lower-attaining young people from advantaged neighbourhoods, while those hypothesised to be most sensitive to the risk embodied by HE were largely unaffected; this is clearly counterintuitive.

Of course, there is no scope for a counterfactual analysis, so it is impossible to know what might have happened to their participation rates if there had been no fee change; it is possible that government efforts to ameliorate the negative elements of the tuition fee rises were successful. However, there is no doubt that disadvantaged young people were substantially less influenced by the cost of HE than predicted. This is consistent with recent studies that have reported a general acceptance of debt among younger students (Esson and Ertl, 2016; Harrison et al., 2015), where debt is not seen as risky as repayment is deferred and means-tested; a concern for the future rather than the present.

\section{Recent trends: youth labour market}

The far-reaching impacts of the 2008 global financial crisis need no rehearsal here, providing the strongest shock to labour markets for a generation or more. One particular manifestation of this was a sharp increase in youth unemployment rates, as can be seen in Figure 2. While the rate has now returned to roughly the pre-crisis level (at around 11 percent), it demonstrates that for several years, 
around one-in-five young people were unemployed, surpassing the recession of the early 1990s. Another trend, beginning prior to the financial crisis, is that the differential between the 18 to 24 and 25 to 49 age groups has steadily grown, such that young people are now around three times as likely to be unemployed, compared to roughly twice in the 1990s.

Figure 2: UK seasonally-adjusted three-month average unemployment rate by age group from 1992 to 2017 (Source: Office for National Statistics 'UNEM01 SA' dataset)

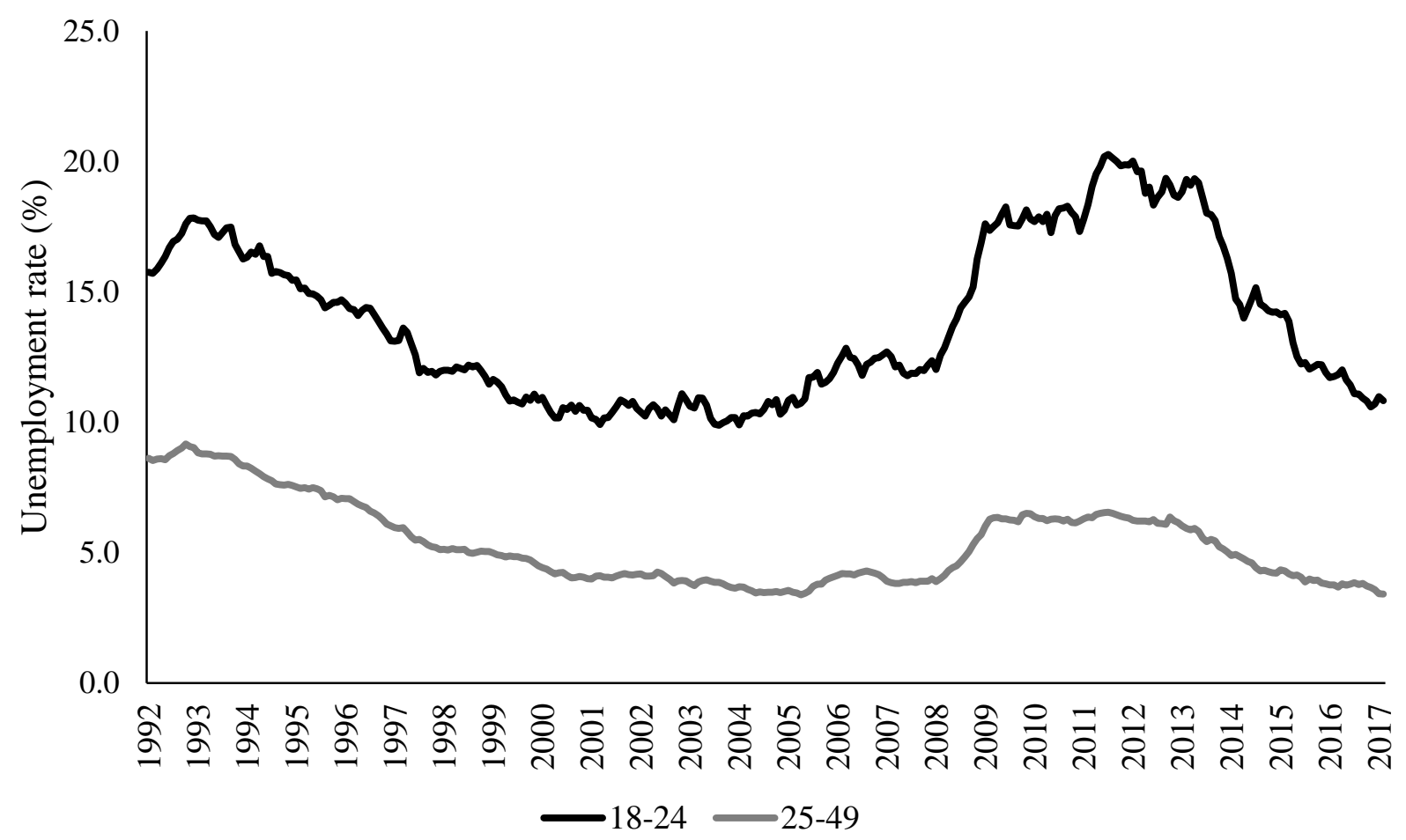

However, while headline unemployment rates have fallen, wage levels have not recovered. Costa and Machin's $(2017,2)$ analysis demonstrates that

young workers have been the ones most affected since the crisis, experiencing a sharp fall in real weekly wages (of the order of $16 \%$ for workers aged 18-21), linked to lower hours, parttime work and self-employment arrangements.

This is an improvement since 2013 when real wages were nearly 30 percent lower than 2008 levels. Furthermore, Ernst and Young (2016) draw attention to the highly localised nature of the recovery in the youth labour market, with some towns and cities (e.g. Middlesbrough, Bradford and Wolverhampton) still experiencing unemployment rates of over 25 percent; specific neighbourhoods will have higher rates still. 
Thus, the youth labour market remains precarious. While more young people are finding work than during the crisis, this is often associated with the so-called 'gig economy' of short-term and part-time work contracts and insecure forms of self-employment. They are also increasingly losing out to older workers.

This period has also seen a shift in the nature of graduate employment. Brown (2013) argues that while the number of graduates has risen sharply in the last fifty years, there has been stagnation in the size of the graduate labour market. This 'opportunity trap' has seen a growing number of graduates frustrated as they enter the job market, with as many as 40 percent enduring lengthy periods in what might be considered non-graduate work (Green and Zhu, 2010; Mosca and Wright, 2011; Purcell et al., 2012). This overqualification may be frustrating for the individual who feels that they are being underemployed (although some may choose non-graduate work), but it also impacts on the structure of the labour market. Drawing on national data, Brynin $(2013,2017)$ demonstrates that some occupations have become 'graduate' just by sheer weight of numbers. He examines 'grey area' occupations which were not historically dominated by graduates, finding that the proportion of graduates working in these occupations has nearly doubled, from 23 percent (1993 to 1995) to 40 percent (2010 to 2012).

This trend has effectively closed the door of many occupational roles to non-graduates through a redesignation of jobs that would previously have been available to school-leavers as 'graduate' jobs, with employers readily able to choose applicants with higher qualifications. Brynin (2017) shows how graduates are increasingly working in the lower service and intermediate occupations; nonmanual roles with good security and prospects for training and promotion. The palette of high-quality opportunities for young people who are not graduates has shrunk rapidly and continues to do so.

\section{Shifting patterns of risk and uncertainty}

The purpose of the preceding two sections has been to marshal data supporting the following four substantive points:

1. There has been an inexorable increase in HE participation to the point where it is now a nearmajority activity for young people in England; 
2. Increases in the cost of HE in 2006 and 2012 do not appear to have reduced the overall participation of young people, nor disproportionately affected those from disadvantaged backgrounds - indeed, the most price-sensitive group appears to have been lower-attaining young people from advantaged backgrounds;

3. Youth unemployment was exceptionally high in the late 2000s and early 2010s, and despite improvements in headline rates, the youth labour market remains precarious, with low wages and poor security;

4. The growth in HE has caused the redefinition of many lower-status jobs as 'graduate' and has significantly reduced access to high-quality jobs for school-leavers.

Based on these points, I will argue in the remainder of this paper that there has been a step-change in the nature of the choices available to young people over the last ten years, culminating in a situation where the previously risky option of $\mathrm{HE}$ has become a secure option in relation to entry to the labour market, and that this plausibly explains the trends seen in the data reported by UCAS (2016) and DfE (2017).

This approach of situating HE within a wider envelope of choices for young people is congruent with Roberts' work on 'opportunity structures' (Roberts, 1968). He argues that decisions are heavily influenced by the structures of localised sociocultural contexts that include family, school, community and labour market. As such, the choices are relational, with young people weighing the various options (and their relative riskiness) as they appear in their context (Evans, 2007; Hodkinson and Sparkes, 1997). Roberts (2009) recognises the shifting structures of late modernity, but continues to argue for their reproductive power within a rational action framework. My argument differs in that it draws on bounded rationality and prospect theory to explain why disadvantaged young people have continued to demand HE in the face of rising costs (and therefore falling net returns).

My argument also shares some features with the concept of 'warehousing' (Grubb and Lazerson, 1982; Walters, 1984) whereby periods of economic downturn see young people extending their education as a means of avoiding unemployment, although this is usually employed in reference to young people with lower qualifications rather than those considering HE (Simmons and Thompson, 2013). The other difference is that warehousing is generally seen as a cyclical phenomenon, with the demand for education falling as jobs become available, whereas I argue that the current situation is defined by a radical realignment between $\mathrm{HE}$ and the youth labour market through a combination the increased risk environment of late modernity, the diversification of $\mathrm{HE}$ and the economic shock of global financial crisis. This is not to argue that these trends are necessarily permanent, but the data 
suggest that something has occurred that cannot be explained by warehousing; in particular, the demand for HE has continued to rise even as the youth labour market has begun to recover.

As we have seen, the alternatives to HE have become limited. The well-paid non-manual jobs with progression prospects that might have been available to previous generations of school-leavers are increasingly occupied by graduates (Brynin, 2013, 2017). Indeed, while their parents may not be graduates, many will have jobs that have become graduate (e.g. nursing or administration). The local labour market may have opportunities for entry to skilled occupations, perhaps through apprenticeships (which are also increasingly competitive - Esson and Ertl, 2016), but in areas of high deprivation, where jobs are scarce, the most realistic alternative to HE may be unskilled casual work or unemployment. Brynin $(2017,110)$ summarises this succinctly from the perspective of young people:

Rising university education creates its own aura, its own magnetism, making more and more jobs seem to be graduate jobs whether or not they are in reality [...] They see an increasing number of jobs becoming graduate so that the risk of not undertaking a university degree seems higher than the risk of taking one.

As discussed above, the financial returns from HE are inherently uncertain, derived from a complex admixture of structural and agentic factors. Partly as a result of long timeframe and issues with counterfactual analysis, it remains unclear what impact the growth of HE has had on the 'graduate premium', with some concluding that it has fallen (e.g. Walker and Zhu, 2008) and others that it has remained broadly constant (e.g. Blundell, Green and Jin, 2016). Naylor, Smith and Telhaj (2016) argue that it has actually risen for high-attaining graduates, while Green and Zhu (2010) argue that lower-attaining graduates are more likely to find themselves overqualified in non-graduate roles and therefore receiving a lower premium; interestingly, relatively few report being unhappy about this, perhaps due to these occupations being in the process of becoming 'graduate' in the way described by Brynin $(2013,2017)$. The role of this overqualification in shaping young people's expectations is moot - it might be expected to influence future generations through a feedback loop about the realities of the graduate labour market, especially for lower-attaining graduates (Green and Zhu, 2010), although Jerrim (2011) reports that young people tend to overestimate the returns. These factors add to perceptions of uncertainty around HE, even if the financial returns are not falling.

However, with just 5 percent unemployment six months after graduation (Higher Education Statistics Agency, 2017), HE does at least offer some certainty of securing work, albeit that this may not be 
graduate-level in the short-term. The rationality of young people's decision-making is bounded (Simon 1979, 1997) by the complexity of a multi-layered decision (which university and which course, et cetera), so a satisficing option is sought - good enough to provide predictability and avoid downward social mobility, but not necessarily optimal. Indeed, it may not necessarily be that they are anticipating upward social mobility due to social congestion (Brown, 2013), but that HE has become essential to maintain their existing social position and standard of living due to the downward drift of graduates within the labour market. This is consistent with the theorisation of Boudon (1974) and later empirical evidence (Stocké, 2007; Obermeier and Schneider, 2015), as well as with Kahneman's (2003) argument that loss-aversion is greatest among those with the lowest economic starting point.

Concurrently with the shift in the graduate labour market, the growth in HE has served to alter public perceptions. With nearly half of all young people participating in a mass system, some of the concerns expressed in the literature from the early 2000s are perhaps less salient than they were. While stark inequalities remain, most universities are substantially more diverse than they were - the principal exception to this rule has been the failure of elite universities to broaden their intake (Harrison, 2017b), with students from lower socio-economic groups and minority ethnic communities still significantly underrepresented (Croxford and Raffe, 2015; Boliver, 2016). This is not to suggest that HE has suddenly become utopian, but it perhaps has become somewhat less daunting and less socially 'risky' as more young people acquire experience of people in their families or communities that have participated, although Jones (2016) does still find significant concerns from 14/15-year-olds in schools lacking a strong tradition of HE entry.

From the perspective of disadvantaged young people, I therefore argue that the recent growth of HE has made participation less socially risky overall and made not participating more financially risky in relative terms - i.e. the risk of participation has risen with rising costs and possibly falling returns, but the risk of non-participation has risen faster. Indeed, this is what some young people directly report, as one young person, then in a further education college, explained in Esson and Ertl's (2016, 1274) study:

There is such high unemployment at the moment for our age group so to not go to university seems like a really silly thing to do, because you are not going to have a job if you don't have these qualifications and that's what is drummed into us from the time that we come to secondary school. That if you don't go to university then you won't have many opportunities and in this climate you don't want to not have a job. 
Others in this study discussed the absence of viable alternatives to $\mathrm{HE}$ and the extreme competition for prestigious apprenticeships that they might otherwise have considered (also see Jones, 2016). This is consistent with the participation trends described above, where changes in the cost of HE have seemingly not impacted significantly on the propensity of disadvantaged young people to participate.

While it is outside the broad argument presented in this paper, it is important to briefly recognise that the nature of participation in HE has changed for young people over the period being explored, and that this is also likely to have a relationship with risk. For example, a higher proportion of young people now choose local institutions so they can to live at home (Holdsworth, 2009). This enables them, inter alia, to reduce living costs, continue pre-existing jobs and maintain strong links to their community, thereby mitigating both financial and social risks to some degree.

\section{Investment, insurance or consumption?}

Under human capital theory (Becker, 1993), extended education (with its actual and opportunity costs) is seen in economic terms as an 'investment' - i.e. resources expended in order to recoup a long-term return. The individual believes that they will benefit financially (and potentially in other ways) from the improved occupational opportunities that will be available to them. This is in contrast to 'consumption' goods which provide an immediate non-financial benefit - e.g. in terms of wellbeing or happiness.

However, I argue that this conceptualisation has become inadequate with respect to young people's decisions about HE. Continuing the argument advanced in the previous section, many may see HE less as an investment (with the implication of a long-term return) and more as a form of insurance that makes future earnings more predictable - i.e. a device for reducing uncertainty rather than necessarily increasing the possibility of a higher salary within an uncertain youth labour market. A degree provides a predictable minimum salary expectation which may not be substantially higher than that available to school-leavers that are able to secure high-quality work with progression opportunities, but it significantly reduces the likelihood of low wage work or unemployment. Of course, participation in HE carries a high opportunity cost of forgone income for three or four years, as well as the need to repay student loans for tuition and maintenance. This does raise the spectre of a potential financial loss from HE, albeit that the student loan system defers repayment until an above- 
average salary is secured and that non-financial gains (e.g. in terms of job satisfaction or flexibility) may outweigh any financial losses.

This desire for certainty is consistent with Ellsberg's (1961) paradox, whereby people tend to prefer options with known probabilities over those with unknown ones, even if the outcomes in the latter instance are likely to be superior. Jones (2016) invokes this to explain non-participation in HE, but I am arguing here that it applies more strongly in the opposite direction - i.e. that while the return-oninvestment for $\mathrm{HE}$ is uncertain, the probability of unemployment is very low compared to the uncertainty of labour market entry, especially in deprived communities and during an economic recession. It is also consistent with the idea of the 'precautionary principle' that is often invoked in studies of risk in complex decisions - 'better safe than sorry', in everyday speech.

The concerns about risk for an advantaged young person are likely to be quite different. While general access to high-quality work or apprenticeships might still be limited, they are likely to have positional advantages derived from their social and economic capital - e.g. tip-offs about opportunities and the ability to travel for interviews. Families may even be able to finance the setting up of a new business or to fund an unpaid internship. Even unemployment might not appear so problematic as a shortterm situation, given the family's economic 'safety net'. The sense of HE as insurance is therefore likely to be stronger among disadvantaged young people.

Indeed, for advantaged young people, their motivation towards HE may, in part, take the form of consumption, purchasing a set of enjoyable social experiences and a chance to develop friendships and interests that may or may not reap rewards in terms of future employability, as well as independence away from the family home (Holdsworth, 2009). Once again, this idea is consistent with what young people say themselves about HE - 'the going out and having a good time' as one advantaged participant in Harrison et al. $(2015,98)$ put it, for example. With consumption goods, there is an element of trading-off between alternative options, and so the growing cost of HE may make other forms of consumption look increasingly attractive at the price (e.g. extended travelling overseas). This may have contributed to the drops in participation among lower-attaining advantaged students that occurred concurrently with rises in the cost of HE (UCAS, 2016; Harrison, 2017b).

\section{Individual perceptions of risk}


While it is not the main thrust of this paper, it is important to acknowledge that the attitudes of individual young people are diverse and situated in their own lives. I have argued that the last decade has seen an overarching shift in perceptions of risk at a societal level, but this does not determine why two young people in ostensibly similar situations might hold contrasting assessments of riskiness and choose differently. There is insufficient space in this paper to discuss this adequately, but I do offer some brief observations.

I have argued within a framework that is informed by Beck's (1992) vision of the 'risk society', with its focus on individual decisions sparking new opportunities for social mobility and reinvention. However, I am also cognisant that the available choices are grounded in persistent social structures that work to delimit what are considered valid or realistic. Burke (2017) argues for the continued importance of Bourdieu's thinking tools of capital, habitus and field (Bourdieu, 1984) and it is easy to see, for example, how these can illuminate which options are familiar to a young person or the depth of the family's safety net. My argument perhaps most closely relates to the formation of habitus that, in turn, guides intuitive decisions taken under uncertainty (Collet, 2009).

Elements of individual personality (e.g. extraversion, openness to new experiences or susceptibility to anxiety) and dispositions are also likely to be salient. For example, Nicholson et al. (2005) point to their importance in predicting perceptions of risk and the willingness to undertake risky activities, identifying a difference between 'risk seekers' and 'risk bearers', while Soane, Dewberry and Narendran (2010) report that personality impacts on individuals' engagement with various forms of risk, including the social and investment domains that are relevant here; Breen et al. (2014) argue that individual levels of risk aversion and discounting over time influence educational decisions. Harrison and Agnew (2016) demonstrate how personality impacts on how individuals view the accumulation of student debt.

Finally, there is significant consensus with the psychology literature (e.g. Byrnes, Miller and Schafer, 1999; Charness and Gneezy, 2012) for a strong relationship between risk and gender, with men generally being found to be significantly more risk-tolerant, which may explain, in part, their higher involvement in extreme sports, gambling and other activities predicated on risk-taking. As noted above, participation in HE is significantly lower amongst young men, ceteris paribus, which would be consistent with greater tolerance of the risks associated with early labour market entry.

\section{Conclusion}


This paper has argued that the prevailing conceptualisations of risk with respect to HE need reconsideration. In particular, changes to the youth labour market caused by the massification of $\mathrm{HE}$ and the 2008 global financial crisis have altered the nature of the choices available to young people. Faced with limited alternatives for well-paid, secure work with progression prospects, HE - even at significantly higher cost and potentially reduced financial returns - has become a markedly less risky option in relative terms. In particular, early labour market entry holds the danger of downward social mobility, which for disadvantaged young people may involve precarious low-quality employment or unemployment.

The alternative view of risk developed in this paper is consistent with, but obviously not proved by, the historical data for HE participation and youth unemployment. Repeated rises in the costs of HE have not deterred disadvantaged young people at the macro scale, with participation rates in 2014 being nearly double those in 2004. As the number of disadvantaged young people participating has increased, the social risk of $\mathrm{HE}$ has declined. One exception to this is the continued failure of elite universities to diversify their intake, such that the social risk at these universities remains unpalatably high for many.

I have argued, therefore, that in the contemporary 'risk society', HE may be viewed by many young people more as a form of insurance than an investment. Young people, especially those who are disadvantaged, may not seek to maximise their long-term returns, in part due to the complexity and uncertainty of the decision envelope: 'the long term is not where life is lived' (Kahneman, 2003, 1457). Rather, they seek to reduce uncertainty through satisficed decisions that are loss-averse and protect against falling standards of living and downward social mobility. This conceptualisation of 'students-as-insurers' provides a new lens for understanding decision-making in a time of global economic turbulence.

The question is not whether HE is considered risky by disadvantaged young people, but rather how this risk is perceived against the risk of not participating. It is this dynamic relationship between HE and the youth labour market that shapes decision-making, and research that fails to recognise this is in danger of presenting a partial and misleading picture. While the recent data suggest that young people are not strongly price-sensitive (except, perhaps, lower-attaining young people from advantaged background), they are highly risk-sensitive, but this spans the inherent uncertainties of all the available choices. I believe that this provides a useful framework for future empirical research, especially if individual differences are also integrated into our understanding. 
Perhaps ironically, the 2012 rise in tuition fees was part of the austerity policies that followed the global financial crisis, but it could only be 'successful' (in terms of still-rising participation rates) due to the changing attitudes to risk resulting from widespread youth unemployment. It is not yet clear whether the die is cast or whether new opportunities will arise outside of HE that rebalance young people's perceptions of risk. If this were to occur, then we might expect to see participation rates among disadvantaged young people fall (as would be predicted by a warehousing argument); a cleft stick for policymakers. In either instance, it would be helpful for government to move away from its misguided construction of young people as rational investors who make optimised decisions about whether and how to enter HE (e.g. DfE, 2016). While it might fit the dominant discourse of HE as a competitive market, it critically misunderstands the nature of young people and how they take important decisions about their lives. 


\section{References}

Archer, L. and M. Hutchings. 2000. “'Bettering Yourself'? Discourses of Risk, Cost and Benefit in Ethnically Diverse, Young Working-Class Non-Participants' Constructions of Higher Education.” British Journal of Sociology of Education 21(4): 555-574.

Archer, L., S.D. Pratt and D. Phillips. 2001. "Working-Class Men's Constructions of Masculinity and Negotiations of (Non)Participation in Higher Education." Gender and Education 13(4): 431-449.

Atfield, G. and K. Purcell. 2010. Job Search Strategies and Employment Preferences of Higher Education Students. Coventry: Institute of Employment Research, University of Warwick.

Atkinson, W. 2007. "Beck, Individualization and the Death of Class: A Critique", British Journal of Sociology 58(3): 349-366.

Ball, S.J., J. Davies, M. David and D. Reay. 2002. “'Classification' and 'Judgement': Social Class and the 'Cognitive Structures' of Choice of Higher Education.” British Journal of Sociology of Education 23(1): 51-72.

Beck, U. 1992. Risk Society: Towards a New Modernity (trans. M. Ritter). London: Sage.

Becker, G.S. 1993. Human Capital: A Theoretical and Empirical Analysis, with Special Reference to Education ( $3^{\text {rd }}$ edition). Chicago: University of Chicago Press.

Blundell, R., D. Green and W. Jin. 2016. The UK Wage Premium Puzzle: How Did a Large Increase in University Graduates Leave the Education Premium Unchanged? London: Institute of Fiscal Studies.

Boliver, V. 2016. "Exploring Ethnic Inequalities in Admission to Russell Group Universities." Sociology 50(2): 247-266.

Boudon, R. 1974. Education, Opportunity and Social Inequality: Changing Prospects in Western Society. London: Wiley.

Bourdieu, P. 1984. Distinction: A Social Critique of the Judgement of Taste. London: Routledge.

Breen, R. and J. Goldthorpe. 1997. "Explaining Educational Differences: Towards a Formal Rational Action Theory." Rationality and Society 9(3): 275-305.

Brown, P. 2013. "Education, Opportunity and the Prospects for Social Mobility." British Journal of Sociology of Education 34(5/6): 678-700.

Brynin, M. 2013. "Individual Choice and Risk: The Case of Higher Education." Sociology 47(2): 284-300.

Brynin, M. 2017. "Higher Education: Too Risky a Decision?” In Access to Higher Education:

Theoretical Perspectives and Contemporary Challenges, edited by A. Mountford-Zimdars and N. Harrison, 101-112. Abingdon: Routledge. 
Burke, C. 2017. "Capitals and Habitus? A Bourdieusian Framework for Understanding Transitions into Higher Education and Student Experiences." In Access to Higher Education: Theoretical Perspectives and Contemporary Challenges, edited by A. Mountford-Zimdars and N. Harrison, 51-66. Abingdon: Routledge.

Byrnes, J.P., D.C. Miller and W.D. Schafer. 1999. “Gender Differences in Risk Taking: A MetaAnalysis.” Psychological Bulletin 125(3): 367-383.

Callender, C. and J. Jackson. 2005. "Does the Fear of Debt Deter Students from Higher Education?" Journal of Social Policy 34(4): 509-540.

Charness, G. and U. Gneezy. 2012. "Strong Evidence for Gender Difference in Risk Taking." Journal of Economic Behaviour \& Organisation 83(1): 50-58.

Clayton, J., G. Crozier and D. Reay. 2009. "Home and Away: Risk, Familiarity and the Multiple Geographies of the Higher Education Experience.” International Studies in Sociology of Education 19(3-4): 157-174.

Collet, F. 2009. “Does Habitus Matter? A Comparative Review of Bourdieu's Habitus and Simon's Bounded Rationality with Some Implications for Economic Sociology." Sociological Theory 27(4): 419-434.

Costa, R. and S. Machin. 2017. Real Wages and Living Standards in the UK. London: London School of Economics.

Croxford, L. and D. Raffe. 2015. “The Iron Law of Hierarchy? Institutional Differentiation in UK Higher Education.” Studies in Higher Education 40(9): 1625-1640.

Department for Education. 2016. Higher Education: Success as a Knowledge Economy. London: Department for Education.

Department for Education. 2017. Widening Participation in Higher Education: 2017. London: Department for Education.

Ellsberg, D. 1961. "Risk, Ambiguity, and the Savage Axioms." Quarterly Journal of Economics 75(4): 643-669.

Ernst and Young. 2016. The Employment Landscape for Young People in the UK: Challenges and Opportunities. London: Ernst and Young.

Evans, K. 2007. "Concepts of Bounded Agency in Education, Work, and the Personal Lives of Young Adults.” International Journal of Psychology 42(2): 85-93.

Esson, J. and H. Ertl. 2016. "No Point Worrying? Potential Undergraduates, Study-Related Debt, and the Financial Allure of Higher Education.” Studies in Higher Education 41(7): 1265-1280.

France, A. 2000. "Towards a Sociological Understanding of Youth and their Risk-Taking", Journal of Youth Studies 3(3): 317-331. 
Furlong, A. and F. Cartmel. 2006. Young People and Social Change: New Perspectives.

Maidenhead: Open University Press.

Green, F. and Y. Zhu. 2010. "Overqualification, Job Dissatisfaction, and Increasing Dispersion in the Returns to Graduate Education." Oxford Economic Papers 62(4): 740-763.

Grubb, W.N. and M. Lazerson. 1982. "Education and the Labor Market: Recycling the Youth Problem.” In Work, Youth and Schooling, edited by H. Kantor and D. Tyack, 110-141. Stanford: Stanford University Press.

Harrison, N. 2017a. "Student Choices Under Uncertainty: Bounded Rationality and Behavioural Economics." In Access to Higher Education: Theoretical Perspectives and Contemporary Challenges, edited by A. Mountford-Zimdars and N. Harrison, 85-100. Abingdon: Routledge. Harrison, N. 2017b. "Patterns of Participation in a Period of Change: Social Trends in English Higher Education from 2000 to 2016.” In Higher Education and Social Inequalities: University Admissions, Experiences, and Outcomes, edited by R. Waller, N. Ingram and M. Ward. Abingdon: Routledge.

Harrison, N. and S. Agnew. 2016. "Individual and Social Influences on Students' Attitudes to Debt: A Cross-National Path Analysis Using Data from England and New Zealand.” Higher Education Quarterly 70(4): 332-353

Harrison, N., F. Chudry, R. Waller and S. Hatt. 2015. “Towards a Typology of Debt Attitudes Among Contemporary Young UK Undergraduates." Journal of Further and Higher Education 39(1): 85-107.

Harrison, N. and C. McCaig. 2015. "An Ecological Fallacy in Higher Education Policy: The Use, Overuse and Misuse of 'Low Participation Neighbourhoods'." Journal of Further and Higher Education 39(6): 793-817.

Higher Education Statistics Agency. 2017. "Destinations of Leavers from Higher Education in the United Kingdom for the Academic Year 2015/16.” Accessed 18 October. http://www.hesa.ac.uk/news/29-06-2017/sfr245-destinations-of-leavers.

Higher Education Statistics Agency. 2018. “Who’s Studying in HE?” Accessed 22 May.

https://www.hesa.ac.uk/data-and-analysis/students/whos-in-he

Hodkinson, P. and A.C. Sparkes. 1997. "Careership: A Sociological Theory of Career Decision Making.” British Journal of Sociology of Education 18(1): 29-44.

Holdsworth, C. 2009. “'Going Away to Uni': Mobility, Modernity, and Independence of English Higher Education Students." Environment and Planning A 41(8): 1849-1864.

Jerrim, J. 2011. “Do UK Higher Education Students Overestimate Their Starting Salary?” Fiscal Studies 32(4): 483-509. 
Jones, R. and L. Thomas. 2005. "The 2003 UK Government Higher Education White Paper: A Critical Assessment of its Implications for the Access and Widening Participation Agenda.” Journal of Education Policy 20(5): 615-630.

Jones, S. 2016. "Expressions of Student Debt Aversion and Tolerance Among Academically Able Young People in Low-Participation English Schools," British Educational Research Journal 42(2): 277-293.

Kahneman, D. 2003. "Maps of Bounded Rationality: Psychology of Behavioural Economics.” American Economic Review 93(5): 1449-1475.

Kahneman, D. and A. Tversky. 1979. "Prospect Theory: An Analysis of Decision Under Risk." Econometrica 47(2): 263-292.

Leathwood, C. and P. O'Connell. 2003. “'It's a Struggle': The Construction of the 'New Student' in Higher Education.” Journal of Education Policy 18(6): 597-615.

Mosca, I. and R. Wright. 2011. Is Graduate Under-Employment Persistent? Evidence from the United Kingdom. Bonn: Institute for the Study of Labor.

National Committee of Inquiry into Higher Education. 1997. Higher Education in the Learning Society. Norwich: HMSO.

Naylor, R., J. Smith and S. Telhaj. 2016. "Graduate Returns, Degree Class Premia and Higher Education Expansion in the UK." Oxford Economic Papers 68(2): 525-545.

Nicholson, N., E. Soane, M. Fenton-O'Creevy and P. Willman. 2005. "Personality and DomainSpecific Risk Taking.” Journal of Risk Research 8(2): 157-176.

Obermeier, V. and T. Schneider. 2015. "Educational Choice and Risk Preferences: How Important is Relative vs. Individual Risk Preference?” Journal for Educational Research Online 7(2): 99128.

Patiniotis, J. and C. Holdsworth. 2005. “'Seize That Chance!' Leaving Home and Transitions to Higher Education.” Journal of Youth Studies 8(1): 81-95.

Purcell, K., P. Elias, G. Atfield, H. Behle, R. Ellison, D. Luchinskaya, J. Snape, L. Conaghan and C. Tzanakou. 2012. Futuretrack Stage 4: Transitions into Employment, Further Study and Other Outcomes. Coventry: University of Warwick.

Raffe, D. and L. Croxford. 2015. "How Stable is the Stratification of Higher Education in England and Scotland?" British Journal of Sociology of Education 36(2): 313-335.

Roberts, K. 1968. "The Entry into Employment: An Approach Towards a General Theory." Sociological Review 16(2): 165-184.

Roberts, K. 2009. “Opportunity Structures Then and Now.” Journal of Education and Work 22(5): 355-368. 
Roberts, S. 2012. "One Step Forward, One Step Beck: A Contribution to the Ongoing Conceptual Debate in Youth Studies.” Journal of Youth Studies 15(3): 389-401.

Robbins, L. 1963. Higher Education. London: HMSO.

Simmons, R. and R. Thompson. 2013. "Reclaiming the Disengaged: Critical Perspectives on Young People not in Education, Employment or Training." Research in Post-Compulsory Education 18(1/2): 1-11.

Simon, H. 1955. “A Behavioural Model of Rational Choice.” Quarterly Journal of Economics 69(1): 99-118.

Simon, H. 1979. "Rational Decision-Making in Business Organisations.” American Economic Review 69(4): 493-513.

Simon, H. 1997. An Empirically Based Microeconomics. Cambridge: Cambridge University Press.

Soane, E., C. Dewberry and S. Narendran. 2010. "The Role of Perceived Costs and Perceived Benefits in the Relationship Between Personality and Risk-Related Choices.” Journal of Risk Research 13(3): 303-318.

Stocké, V. 2007. “Explaining Educational Decision and Effects of Families' Social Class Position: An Empirical Test of the Breen-Goldthorpe Model of Educational Attainment." European Sociological Review 23(4): 505-519.

Thomas, L. 2012. Building Student Engagement and Belonging in Higher Education at a Time of Change: Final Report from the What Works? Student Retention \& Success Programme. London: Paul Hamlyn Foundation.

Thompson, R. 2017. "Explaining Inequality? Rational Action Theories of Educational Decision Making." In Access to Higher Education: Theoretical Perspectives and Contemporary Challenges, edited by A. Mountford-Zimdars and N. Harrison, 67-84. Abingdon: Routledge. Universities and Colleges Admissions Service. 2016. End of Cycle Report 2016. Cheltenham: UCAS.

Walker, I. and Y. Zhu. 2008. "The College Wage Premium and the Expansion of Higher Education in the UK." Scandinavian Journal of Economics 110 (4): 695-709.

Walker, I. and Y. Zhu. 2011. "Differences by Degree: Evidence of the Net Financial Rates of Return to Undergraduate Study for England and Wales." Economics of Education Review 30(6): 1177-1186.

Walters, P.B. 1984. “Occupational and Labor Market Effects on Secondary and Postsecondary Educational Expansion in the United States: 1922 to 1979.” American Sociological Review 49(5): 659-671. 
Whitty, G., A. Hayton and S. Tang. 2015. "Who You Know, What You Know and Knowing the Ropes: A Review of Evidence About Access to Higher Education Institutions in England.” Review of Education 3(1): 27-67.

Woodman, D. 2009. “The Mysterious Case of the Pervasive Choice Biography: Ulrich Beck, Structure/Agency, and the Middling State of Theory in the Sociology of Youth." Journal of Youth Studies 12(3): 243-256. 